\title{
Prevalence of and factors associated with early initiation of breastfeeding among women with children aged $<24$ months in Kilimanjaro region, northern Tanzania: a community-based cross-sectional study
}

Farida Ali ${ }^{1^{*}}$ (D), Melina Mgongo ${ }^{2,3}$, Redempta Mamseri ${ }^{3}$, Johnston M. George ${ }^{3}$, Innocent B. Mboya ${ }^{1,3,4}$ and Sia E. Msuya $a^{2,3,5}$

\begin{abstract}
Background: Early initiation of breastfeeding offers nutritional and immunological benefits to the newborn, which is critical for health and survival. Understanding factors associated with timely initiation of breastfeeding is crucial for healthcare providers and policy-makers. This study aimed to assess the prevalence and factors associated with early initiation of breastfeeding among mothers with children $<24$ months of age in the Kilimanjaro region, Northern Tanzania.

Methods: This study utilized secondary data from a cross-sectional survey conducted in April 2016 and April 2017 in the Kilimanjaro region. A multistage sampling technique was used to select study participants and interviewed using a questionnaire. A total of 1644 women with children aged $<24$ months were analyzed. Modified Poisson regression models were used to determine factors independently associated with early initiation of breastfeeding, within first hour of life.

Results: The prevalence of early initiation of breastfeeding in the Kilimanjaro region was 70\%, ranging from 64\% in Same to $80 \%$ in Siha districts. The prevalence of early initiation of breastfeeding was lower among women who initiated prelacteal feeding compared to their counterparts (prevalence ratio [PR] 0.42; 95\% Confidence Interval [CI] $0.34,0.53)$. Likewise, women living in Same and Hai district had lower prevalence of early initiation of breastfeeding compared to women in Rombo (PR 0.8; $95 \% \mathrm{Cl} 0.76,0.93$ ) and (PR 0.89, 95\% Cl 0.80, 0.98) respectively. Higher prevalence of early initiation of breastfeeding was found in women with primary education compared to those with secondary education (PR 1.09; 95\% Cl 1.003, 1.18), and among women with two children compared to one child (PR 1.14, $95 \% \mathrm{Cl} 1.03,1.26)$.

(Continued on next page)
\end{abstract}

\footnotetext{
* Correspondence: allyfarry02@gmail.com

${ }^{1}$ Institute of Public Health, Department of Epidemiology and Biostatistics, Kilimanjaro Christian Medical University College (KCMUCo), P. O. Box 2240, Moshi, Tanzania

Full list of author information is available at the end of the article
}

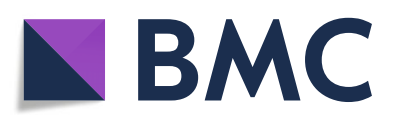

(c) The Author(s). 2020 Open Access This article is licensed under a Creative Commons Attribution 4.0 International License, which permits use, sharing, adaptation, distribution and reproduction in any medium or format, as long as you give appropriate credit to the original author(s) and the source, provide a link to the Creative Commons licence, and indicate if changes were made. The images or other third party material in this article are included in the article's Creative Commons licence, unless indicated otherwise in a credit line to the material. If material is not included in the article's Creative Commons licence and your intended use is not permitted by statutory regulation or exceeds the permitted use, you will need to obtain permission directly from the copyright holder. To view a copy of this licence, visit http://creativecommons.org/licenses/by/4.0/ The Creative Commons Public Domain Dedication waiver (http://creativecommons.org/publicdomain/zero/1.0/) applies to the data made available in this article, unless otherwise stated in a credit line to the data. 


\begin{abstract}
(Continued from previous page)
Conclusions: Early initiation of breastfeeding practice was suboptimal in this study. To improve early initiation of breastfeeding, healthcare providers at reproductive and child health clinics and labour wards should discourage women from prelacteal feeding, give more support to women with one child and those with secondary level of education and above. Furthermore, a qualitative study is crucial to understand the reasons for low prevalence of early initiation of breastfeeding in Same and Hai districts.
\end{abstract}

Keywords: Breastfeeding, Early initiation of breastfeeding, Prevalence

\section{Background}

Early initiation of breastfeeding refers to initiation of breastfeeding within $1 \mathrm{~h}$ after birth [1]. The practice gives the best start in life a chance of infant to receive colostrum as a first diet and confers benefits that last for a lifetime [2]. Colostrum is highly rich in nutrients that help child growth and has antibodies that act as a first vaccine hence protects the newborn from infection [2]. Other benefits for the child include; body temperature and glucose regulation and stimulates more milk production. Early initiation of breastfeeding also introduces skin to skin contact with the mother, which is reported to extend the duration of breastfeeding and contributing to an increase in exclusive breastfeeding. For mothers, early initiation of breastfeeding stimulate contraction of uterus after child birth, which reduces the risk of postpartum hemorrhage [2].

Delayed initiation of breastfeeding increases the risk of neonatal morbidity and mortality. Evidence from a systematic review conducted in Ghana, India, and Tanzania showed that infants who initiated breastfeeding more than $1 \mathrm{~h}$ after delivery had 50 and $11 \%$ higher risk of cough and breathing difficulties, respectively, during the first 6 months of life compared to those who began within $1 \mathrm{~h}$ after birth [3]. Also, neonates who started breastfeeding 2-23 $\mathrm{h}$ after birth had a $33 \%$ greater risk of dying compared to those who began within $1 \mathrm{~h}$ after delivery, and

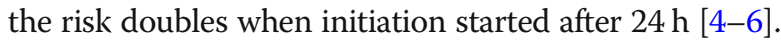

Despite these benefits of early initiation of breastfeeding, globally, only $42 \%$ of the newborns initiated breastfeeding within $1 \mathrm{~h}$ after birth in 2018 [2]. In the WHO European region, the overall prevalence of early initiation of breastfeeding was $43 \%$ [7]. At the same time, in low- middleincome countries, it ranged from $35 \%$ in the Middle East and North Africa to 65\% in Eastern Southern Africa regions [2]. Prevalence in African countries varies from $34.7 \%$ in Nigeria and $87.2 \%$ in Sudan [8-13].

Early initiation of breastfeeding is one of the costeffective interventions to reduce neonatal mortality and morbidity. However, in Tanzania, the prevalence of early initiation of breastfeeding was $51 \%$, while in northern Tanzania, the prevalence was $73.2 \%$ ranging between $28 \%$ in Simiyu and $80 \%$ in Tanga regions, while in Kilimanjaro region the prevalence was 73.7\% [14]. These estimates are still far from the set target of $90 \%$ by 2020 . Tanzania Demographic and Health Survey (TDHS) estimated the neonatal mortality of 25 deaths per 1000 live births, which is higher than the national target of reducing this rate to 16 deaths per 1000 live births by 2020 [14] and Sustainable Development Goals (SDGs) target of 12 deaths per 1000 live births reduction by 2030 [15]. The mortality situation indicates a missed opportunity to use early initiation of breastfeeding as one of the interventions to improve newborn survival.

Tanzania has established the road map strategic plan activities for improving early initiation of breastfeeding. These activities include capacitating healthcare providers in assisting women in initiating breastfeeding within $1 \mathrm{~h}$ after birth, improving antenatal care coverage, and training community healthcare workers at all levels on the importance of early initiation of breastfeeding techniques [16]. Despite these interventions, the country is far from reaching the national target of increasing early initiation of breastfeeding from $51 \%$ in 2016 to $90 \%$ by 2020 [16]. Likewise, in the Kilimanjaro region, where the proportion of hospital delivery is $91 \%$, and delivery by skilled birth attendants is the highest (96\%), early initiation of breastfeeding is still suboptimal [14].

Different factors are reported to be positively associated with early initiation of breastfeeding practice, these include; health facility delivery $[8,11]$, assistance by a skilled birth attendant [10, 17], multiparous [10, 12], and counseling on early initiation of breastfeeding during antenatal care [18]. Factors such as prelacteal feeding [19], caesarean section delivery [11, 12, 16, 20,21], having no formal education [22], delivering a male child [9], and being unmarried were negatively associated with early initiation of breastfeeding $[13,23]$. There are variations of factors that influence early initiation of breastfeeding from one setting to another within and between countries due to differences in cultural, socio-economic conditions, and health inequalities as well as the quality of healthcare services. Understanding context-specific factors will inform targeted interventions to improve early initiation of breastfeeding. This study aimed to assess prevalence and factors associated with early initiation of breastfeeding among mothers with children aged $<24$ months in the Kilimanjaro region, Northern Tanzania. The researchers conducted study to determine 
sociodemographic, reproductive and health utilization services, child characteristics and breastfeeding pattern factors associated with early initiation if breastfeeding.

\section{Methods}

\section{Study design and setting}

This community-based cross-sectional study utilized data from a study that aimed to assess infant and young child feeding practices among children under 5 years of age in the Kilimanjaro region, Northern Tanzania. The study was conducted in April 2016 and April 2017 in six districts out of seven in the Kilimanjaro region, namely; Moshi Municipal, Rombo, Same, Mwanga, Hai, and Siha. We analyzed data for women with children aged 0-23 months, who had ever breastfed and who reported time of initiation of breastfeeding at the time of the interview.

Kilimanjaro region is among the 30 administrative regions in Tanzania Mainland with an area size of 13,250 $\mathrm{km}^{2}$. This region is located in the Northern part of the country and has a population of approximately 1,640,000 people, 845,000 (51.6\%) being females. More than threequarters of the population reside in rural areas [24]. Agriculture and livestock keeping are the main economic activities but are complemented by tourism, manufacturing, and business activities. The region has 18 hospitals, 51 health centers, and 333 dispensaries, which are owned by the Government, faith-based organizations, or private institutions/ individuals. These facilities offer preventive, curative, and rehabilitative services, including maternal and child health services such as antenatal care, postnatal care, family planning, delivery, child growth monitoring, and vaccination services among others. According to Tanzania Demographic and Health Survey (TDHS), a vast majority of deliveries $(92 \%)$ in the region are conducted by skilled birth attendants, but the proportion of women who attend four antenatal care visits is low (25\%) [14].

\section{Study population, sample size, and sampling}

The parent study enrolled 3079 women with children aged less than 5 years. The current study included women with children aged 0-23 months, with complete information on early initiation of breastfeeding and mothers who came with their infants. Data for 1644 women were, therefore, analyzed in this study (Fig. 1). A multistage sampling technique was used to select participants from each of the six districts. One district (Moshi rural) was purposively excluded because there was an ongoing study investigating anemia in under-five children. In the second stage, three villages (in rural areas) or streets (in urban areas) were randomly selected from each ward. The third stage involved a listing of households with children under 5 years with the help of ward/ village and street leaders/ or link persons, followed by a random selection of households. At the household level, one child was selected. If the household had more than one under-five child, the youngest child was selected.

\section{Variables}

The outcome variable is the early initiation of breastfeeding (EIBF). Early initiation of breastfeeding was measured by asking the mother whether she had ever breastfed the baby, and if yes, time in hours when the child was initiated breastfeeding. This was expressed as a dichotomous variable with 1 representing initiation of breastfeeding within $1 \mathrm{~h}$ after birth and 0 if otherwise.

Independent variables analyzed in this study included: sociodemographic characteristics of both the mother and the child, reproductive characteristics, and breastfeeding patterns. Sociodemographic characteristics included the district of residence (Rombo, Moshi Urban, Same, Mwanga, Hai, and Siha); area of residence (urban, rural); maternal age in years $(15-24,25-34,35-49)$; marital status (single, married/cohabiting, divorced/widow); education level (no education, primary, secondary and above) and employment status (whether employed or not). Reproductive and Maternal Health Services included parity, number of antenatal care visits $(<4, \geq 4)$; breastfeeding counseling during antenatal care visits (yes, no), breastfeeding support after birth (yes, no), place of birth (health facilities, home/others) and level of health facility of delivery (dispensary, health center, hospital). Child characteristics included child age in months $(0-11$, 12-23), sex (male, female), and birthweight in kilograms $(<2.5 \mathrm{~kg}$ and $\geq 2.5 \mathrm{~kg})$ while breastfeeding patterns included prelacteal feeding (yes, no) and use of colostrum (yes, no).

\section{Data collection method and tools}

Face-to-face interviews was the method used to collected data using a questionnaire. The questionnaire collected information on sociodemographic characteristics of the mother and the child, food security at the household level, reproductive health information, breastfeeding patterns, the use of health facilities during pregnancy with the child involved in the study, history of infections, and treatment, customs, and attitude towards early initiation of breastfeeding. The questionnaire was in both English and Swahili languages but administered using the Swahili language, a language spoken by all the local people in this setting. Trained medical students from KCMUCo collected data following participant informed consent.

\section{Data analysis}

Data were cleaned and analyzed using Stata version 15. Continuous variables were summarized using mean/ median with standard deviation/ interquartile range, respectively, and categorical variables using frequencies and percentages. Modified Poisson regression 


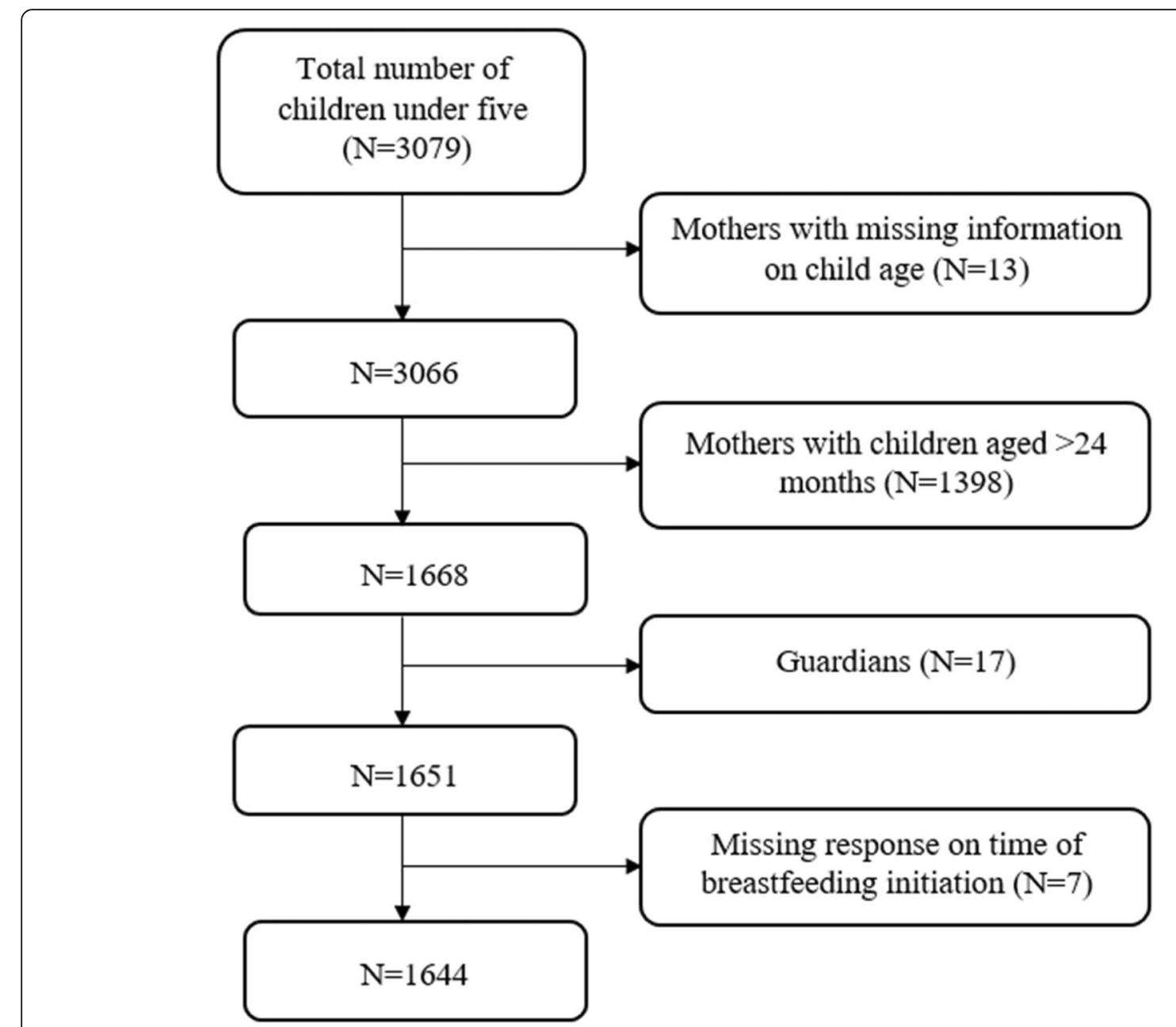

Fig. 1 Schematic diagram showing sample size used in the analysis

whose measure of association is prevalence ratio (PR) was used as an alternative to classical logistic regression because the prevalence of early initiation of breastfeeding was common (>10\%). Prevalence ratio is defined as the probability of prevalence of diseases among exposures over prevalence of disease among unexposed. Bivariate and multivariable regression models were used to identify factors associated with early initiation of breastfeeding. Independent variables with $p<0.05$ in the bivariate analysis were entered in the multivariable model to adjust for the potential confounding effect. We used stepwise regression for model building whereby covariates were added and removed from the model by forwarding elimination. The statistically significant $p$ - values of Wald test statistics for each covariate determined retention of the variable in the model. We used the likelihood ratio test to compare nested models. The strength of association was expressed using PR and their 95\% confidence intervals. Variables with $p<0.05$ in multivariable analysis were considered to be associated with early initiation of breastfeeding.

\section{Results}

Respondent characteristics

A total of 1644 mother-child-pairs were included in this analysis. The mean age \pm SD of mothers was $28 \pm 7$ years, and $44.7 \%$ were aged between 25 and 34 years. More than three quarters were rural residents, $73.9 \%$ were married/ cohabiting with their partners, $62.1 \%$ had primary education level, and majorities $(86.3 \%)$ were not employed. About $60 \%$ of their partners had primary education level (Table 1).

\section{Reproductive characteristics and utilization of maternal health service use}

More than one-third of all mothers had one child with a median parity of 2 (IQR 1,3 ). The majority (76.9\%) had $\geq 4$ antenatal visits, received breastfeeding 
Table 1 Sociodemographic characteristics of study participants, $N=1644$

\begin{tabular}{|c|c|c|}
\hline Variable & Frequency & Percentage \\
\hline \multicolumn{3}{|l|}{ District of residence } \\
\hline Rombo & 372 & 22.6 \\
\hline Moshi urban & 170 & 10.3 \\
\hline Same & 355 & 21.6 \\
\hline Mwanga & 179 & 10.9 \\
\hline Hai & 296 & 18.0 \\
\hline Siha & 272 & 16.6 \\
\hline \multicolumn{3}{|l|}{ Area of residence $^{a}$} \\
\hline Urban & 365 & 22.2 \\
\hline Rural & 1278 & 77.8 \\
\hline \multicolumn{3}{|l|}{ Maternal age in years ${ }^{a}$} \\
\hline $15-24$ & 609 & 37.2 \\
\hline $25-34$ & 733 & 44.7 \\
\hline $35-49$ & 297 & 18.1 \\
\hline Mean \pm SD & $28 \pm 7$ & \\
\hline \multicolumn{3}{|l|}{ Marital status $^{\mathrm{a}}$} \\
\hline Married & 1213 & 73.9 \\
\hline Single & 357 & 21.7 \\
\hline Divorced/widow & 72 & 4.4 \\
\hline \multicolumn{3}{|c|}{ Maternal education level $^{\mathrm{a}}$} \\
\hline Non-formal & 56 & 3.4 \\
\hline Primary & 1020 & 62.1 \\
\hline Secondary and above & 566 & 34.5 \\
\hline \multicolumn{3}{|l|}{ Employed with salary ${ }^{a}$} \\
\hline No & 1418 & 86.4 \\
\hline Yes & 224 & 13.6 \\
\hline \multicolumn{3}{|l|}{ Partner education level ${ }^{a}$} \\
\hline Non-formal & 40 & 2.8 \\
\hline Primary & 849 & 58.9 \\
\hline Secondary and above & 552 & 38.3 \\
\hline
\end{tabular}

${ }^{\mathrm{a}}$ Frequencies do not tally to the total due to missing values in these variables

counseling at antenatal (64.8\%), while $28.5 \%$ received breastfeeding support immediately after birth, and 87.1\% delivered at the health facilities. Out of 1541 who delivered at the health facilities, $62.2 \%$ delivered at the hospital (Table 2).

\section{Child characteristics and breastfeeding patterns}

The mean age \pm SD of children in this study was $11 \pm$ 7 months, and more than half $(52.7 \%)$ were aged $\leq 11$ months. Half of all children were females. The vast majority (93\%) had a birthweight of $2.5 \mathrm{Kg}, 95.9 \%$ were given colostrum, and only $11 \%$ were given prelacteal feeds (Table 3 ).
Table 2 Reproductive characteristics of study participants, $N=1644$

\begin{tabular}{lll}
\hline Variable & Frequency & Percentage \\
\hline Parity $^{\mathbf{a}}$ & & \\
1 & 565 & 34.4 \\
2 & 428 & 26.0 \\
$\geq 3$ & 650 & 39.6 \\
Median (IQR) & $2(1,3)$ & \\
Number of antenatal care visits & \\
$<4$ & 376 & \\
$\geq 4$ & 1254 & 23.1 \\
\end{tabular}

Antenatal care breastfeeding counseling ${ }^{a}$

No $\quad 573 \quad 35.2$

$\begin{array}{lll}\text { Yes } & 1054 & 64.8\end{array}$

Place of birth ${ }^{a}$

Health facility $\quad 1418 \quad 87.1$

Home/Others $\quad 209 \quad 12.9$

Level of health facility of birth $(n=765)^{a}$

$\begin{array}{lll}\text { Dispensary } & 190 & 12.3 \\ \text { Health center } & 392 & 25.5 \\ \text { Hospital } & 959 & 62.2\end{array}$

Breastfeeding support immediately after birth by provider $^{\mathrm{a}}$

\begin{tabular}{ccc} 
No & 611 & 71.5 \\
Yes & 244 & 28.5 \\
\hline a Frequencies do not tally to the total due to missing values in these variables
\end{tabular}

\section{Prevalence of early initiation of breastfeeding}

The prevalence of early initiation of breastfeeding was $70 \%$. The prevalence ranged between $63.7 \%$ in the Same district and $79.8 \%$ in the Siha district council (Fig. 2).

\section{Factors associated with early initiation of breastfeeding}

In bivariate analysis, the district of residence, mother's and partner's education level, parity, and prelacteal feed were the factors significantly $(p<0.05)$ associated with early initiation of breastfeeding. Prevalence of early initiation of breastfeeding was $13 \%$ lower among women in Same and Hai district compared to Rombo district, (PR 0.87; 95\% CI 0.79, 0.96) and (PR 0.87, 95\% CI 0.79, 0.97) respectively. Prevalence was $12 \%$ higher among women who had given birth to two children and $10 \%$ higher among women who had given birth more than twice compared to those who gave birth once (PR 1.12; 95\% CI 1.02, 1.21) and (PR 1.10; 95\% CI 1.01, 1.19), respectively. Women with primary education level had an $11 \%$ higher prevalence of early initiation of breastfeeding compared to those who had no formal education (PR 1.11; 95\% CI 1.03, 1.19). Likewise, women whose partners had primary education level had an $8 \%$ higher prevalence of early initiation of breastfeeding compared 
Table 3 Child characteristics and breastfeeding patterns, $N=1644$

\begin{tabular}{|c|c|c|}
\hline Variable & Frequency & Percent \\
\hline \multicolumn{3}{|l|}{ Age in months } \\
\hline $0-11$ & 872 & 52.7 \\
\hline $12-23$ & 783 & 47.3 \\
\hline Mean \pm SD & $11 \pm 7$ & \\
\hline \multicolumn{3}{|l|}{ Sex } \\
\hline Male & 814 & 49.5 \\
\hline Female & 829 & 50.5 \\
\hline \multicolumn{3}{|l|}{ Birthweight in kilograms (Kgs) } \\
\hline$<2.5$ & 113 & 7.0 \\
\hline$\geq 2.5$ & 1498 & 93.0 \\
\hline \multicolumn{3}{|l|}{ Breastfeeding initiation } \\
\hline Early initiation (within $1 \mathrm{~h}$ after birth) & 1150 & 70.0 \\
\hline Late initiation (after $1 \mathrm{~h}$ ) & 494 & 30.0 \\
\hline \multicolumn{3}{|l|}{ Child given prelacteal feed ${ }^{a}$} \\
\hline No & 1467 & 89.2 \\
\hline Yes & 176 & 10.8 \\
\hline \multicolumn{3}{|l|}{ Child given colostrum $^{a}$} \\
\hline No & 69 & 4.1 \\
\hline Yes & 1574 & 95.9 \\
\hline
\end{tabular}

${ }^{a}$ Variables with missing information

to those whose partners had no formal education (PR 1.08 ; $95 \%$ CI $0.89,1.32$ ). Also, the prevalence of early initiation of breastfeeding was $59 \%$ lower among women who introduced prelacteal feeding (PR 0.41; 95\% CI 0.33, 0.51) compared to those who did not (Table 4).

In multivariable analysis, the district of residence, mother's education level, parity, and prelacteal feeding were the factors independently associated with early initiation of breastfeeding (Table 4). Prevalence of early initiation of breastfeeding was 16\% (PR 0.84; 95\% CI $0.76,0.93$ ) and $11 \%$ (PR 0.89; 95\% CI 0.80, 0.98) lower for women in Same and Hai districts, respectively compared to those in Rombo district. Women with primary education level had a 9\% higher prevalence of early initiation of breastfeeding compared to those who had no formal education (PR 1.09; 95\% CI 1.003, 1.18). Women who had given birth to two children had a $12 \%$ higher prevalence of early initiation of breastfeeding compared to primiparous mothers (PR 1.12, 95\% CI 1.02, 1.21). Mothers who gave their children prelacteal feeds had a $58 \%$ lower prevalence of early initiation of breastfeeding (PR 0.42; 95\% CI 0.34, 0.53) compared to those who did not give.

\section{Discussion}

The prevalence of early initiation of breastfeeding (EIBF) was $70 \%$. District of residence, women education level, parity, and prelacteal feeding were the factors independently associated with early initiation of breastfeeding in this setting.

Based on the WHO classification of percentages of breastfeeding within $1 \mathrm{~h}$ after delivery as (0-29) poor, (30-49) fair, (50-89) good and (90-100) very good, the prevalence obtained in this study is good [25] and higher than that reported in a study conducted in Rufiji, Kilombero and Ulanga districts if Tanzania [26] as well as national level findings of $51 \%$ [14]. However, these results show a missed opportunity to promote early initiation of breastfeeding because about $90 \%$ of deliveries in the Kilimanjaro region are assisted by the skilled birth attendants [14]. This call to healthcare providers to further assist and promote early initiation of breastfeeding.

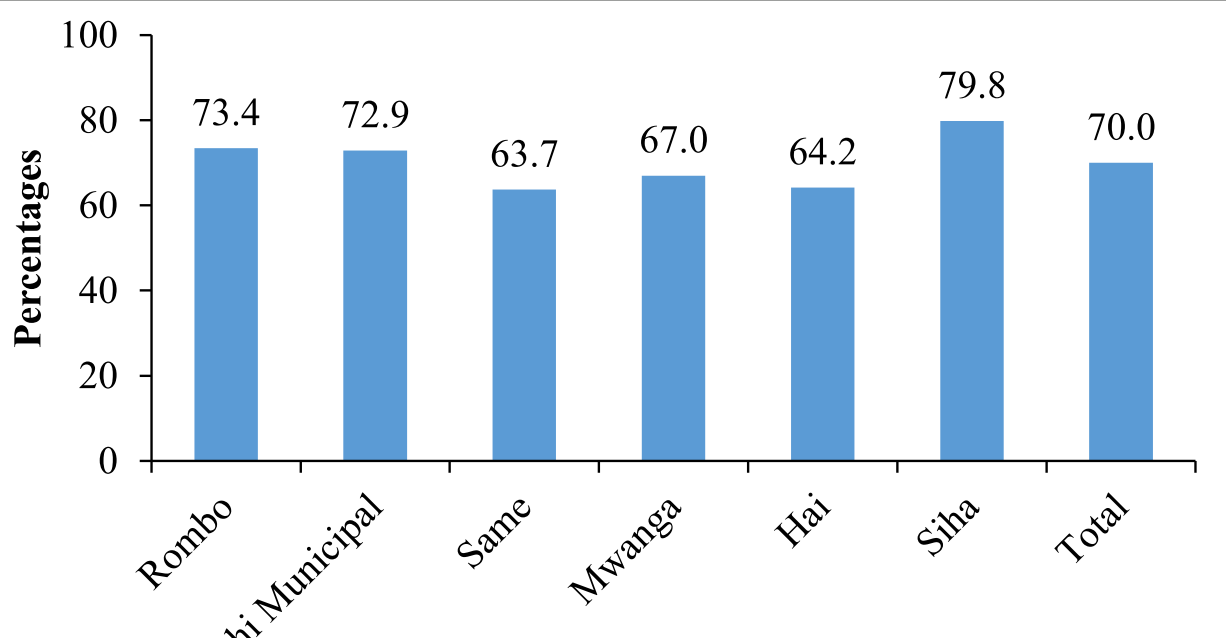

Districts

Fig. 2 Early Initiation of Breastfeeding by districts in the Kilimanjaro region $(N=1644)$ 
Table 4 Factors associated with early initiation of breastfeeding, $N=1644$

\begin{tabular}{|c|c|c|c|c|c|c|}
\hline Variable & $n$ & $\begin{array}{l}\text { EIBF } \\
n(\%)\end{array}$ & CPR $(95 \% \mathrm{Cl})$ & $P$-value & APR $(95 \% \mathrm{Cl})$ & $P$-value \\
\hline \multicolumn{7}{|l|}{ District } \\
\hline Rombo & 372 & $273(73.4)$ & 1 & & 1 & \\
\hline Moshi urban & 170 & $124(72.9)$ & $0.99(0.89,1.11)$ & 0.914 & $0.99(0.89,1.10)$ & 0.848 \\
\hline Same & 355 & $226(63.7)$ & $0.87(0.79,0.96)$ & 0.005 & $0.84(0.76,0.93)$ & 0.001 \\
\hline Mwanga & 179 & $120(67.0)$ & $0.91(0.81,1.03)$ & 0.138 & $0.92(0.81,1.05)$ & 0.203 \\
\hline Hai & 296 & $190(64.2)$ & $0.87(0.79,0.97)$ & 0.012 & $0.89(0.80,0.98)$ & 0.024 \\
\hline Siha & 272 & $217(79.8)$ & $1.09(1.00,1.19)$ & 0.056 & $1.07(0.98,1.17)$ & 0.156 \\
\hline \multicolumn{7}{|l|}{ Residence } \\
\hline Urban & 365 & $255(69.9)$ & 1 & & & \\
\hline Rural & 1279 & $895(70.0)$ & $1.00(0.93,1.08)$ & 0.967 & & \\
\hline \multicolumn{7}{|l|}{ Maternal age (years) } \\
\hline $15-24$ & 609 & $416(68.3)$ & 1 & & & \\
\hline $25-34$ & 734 & $513(69.9)$ & $1.02(0.95,1.10)$ & 0.533 & & \\
\hline $35-49$ & 298 & $218(73.2)$ & $1.07(0.98,1.17)$ & 0.125 & & \\
\hline \multicolumn{7}{|l|}{ Child age (months) } \\
\hline $0-11$ & 871 & $607(69.7)$ & 1 & & & \\
\hline $12-23$ & 773 & $543(70.3)$ & $1.01(0.94,1.07)$ & 0.819 & & \\
\hline \multicolumn{7}{|l|}{ Child sex } \\
\hline Female & 814 & $564(69.3)$ & $1.02(0.96,1.09)$ & 0.572 & & \\
\hline Male & 829 & $585(70.6)$ & 1 & & & \\
\hline \multicolumn{7}{|l|}{ Marital status } \\
\hline Married & 1213 & $866(71.4)$ & 1 & & & \\
\hline Single & 357 & $239(67.0)$ & $0.94(0.86,1.02)$ & 0.12 & & \\
\hline Divorced/widow & 72 & $43(59.7)$ & $0.83(0.69,1.01)$ & 0.07 & & \\
\hline \multicolumn{7}{|l|}{ Maternal education } \\
\hline No formal & 56 & $40(71.4)$ & $1.09(0.92,1.30)$ & 0.324 & $1.00(0.82,1.24)$ & 0.933 \\
\hline Primary & 1020 & $739(72.5)$ & $1.11(1.03,1.19)$ & 0.005 & $1.09(1.003,1.18)$ & 0.043 \\
\hline Secondary \& above & 566 & $370(65.4)$ & 1 & & 1 & \\
\hline \multicolumn{7}{|l|}{ Employed with salary } \\
\hline No & 1418 & $1000(70.6)$ & 1 & & & \\
\hline Yes & 224 & $148(66.1)$ & $0.93(0.85,1.03)$ & 0.193 & & \\
\hline \multicolumn{7}{|l|}{ Partner education } \\
\hline No formal & 40 & $29(72.5)$ & $1.08(0.89,1.32)$ & 0.441 & $1.04(0.84,1.28)$ & 0.743 \\
\hline Primary & 849 & $614(72.3)$ & $1.08(1.004,1.16)$ & 0.038 & $1.03(0.60,1.11)$ & 0.399 \\
\hline Secondary \& above & 552 & $370(67.0)$ & 1 & & 1 & \\
\hline \multicolumn{7}{|l|}{ Parity } \\
\hline 1 & 565 & $364(64.4)$ & 1 & & 1 & \\
\hline 2 & 428 & $326(76.2)$ & $1.18(1.09,1.28)$ & $<0.001$ & $1.12(1.02,1.21)$ & 0.011 \\
\hline$\geq 3$ & 650 & $459(70.6)$ & $1.10(1.01,1.19)$ & 0.023 & $1.03(0.94,1.12)$ & 0.523 \\
\hline \multicolumn{7}{|c|}{ Frequency of ANC care } \\
\hline$<4$ & 376 & $255(67.8)$ & 1 & & & \\
\hline$\geq 4$ & 1254 & 885 (70.6) & $1.04(0.96,1.13)$ & 0.319 & & \\
\hline
\end{tabular}

BF counseling at ANC 
Table 4 Factors associated with early initiation of breastfeeding, $N=1644$ (Continued)

\begin{tabular}{|c|c|c|c|c|c|c|}
\hline Variable & $n$ & $\begin{array}{l}\text { EIBF } \\
n(\%)\end{array}$ & CPR $(95 \% \mathrm{Cl})$ & $P$-value & APR $(95 \% \mathrm{Cl})$ & $P$-value \\
\hline No & 573 & $392(68.4)$ & 1 & & & \\
\hline Yes & 1054 & $742(70.5)$ & $1.03(0.96,1.10)$ & 0.388 & & \\
\hline \multicolumn{7}{|l|}{ Place of birth } \\
\hline Home/others & 209 & $137(65.6)$ & $0.93(0.84,1.03)$ & 0.174 & & \\
\hline Health facility & 1415 & $999(70.5)$ & 1 & & & \\
\hline \multicolumn{7}{|c|}{ Child birthweight (Kg) } \\
\hline$<2.5$ & 113 & $72(63.7)$ & 1 & & & \\
\hline$\geq 2.5$ & 1498 & $1059(70.7)$ & $1.11(0.96,1.28)$ & 0.154 & & \\
\hline \multicolumn{7}{|c|}{ BF support immediately after delivery by provider } \\
\hline No & 611 & $438(71.7)$ & 1 & & & \\
\hline Yes & 244 & $166(68.0)$ & $0.95(0.86,1.05)$ & 0.303 & & \\
\hline \multicolumn{7}{|c|}{ Prelacteal feeding } \\
\hline No & 1457 & $1088(74.7)$ & 1 & & 1 & \\
\hline Yes & 176 & $54(30.7)$ & $0.41(0.33,0.51)$ & $<0.001$ & $0.42(0.34,0.53)$ & $<0.001$ \\
\hline \multicolumn{7}{|c|}{ Child given colostrum } \\
\hline No & 68 & $40(58.8)$ & $1.20(0.98,1.46)$ & 0.081 & & \\
\hline Yes & 1574 & $1108(70.4)$ & 1 & & & \\
\hline
\end{tabular}

EIBF Early Initiation of breastfeeding, BF Breastfeeding, HF Health Facility, CPR Crude Prevalence ratio, APR Adjusted Prevalence Ratio

In low- and middle-income countries such as India, Bangladesh, Ethiopia, and South Sudan, the prevalence ranges between 40 and $51 \%,[6,13,26-29]$ which was lower than that reported in this study. The prevalence reported in Saudi Arabia was also low [21]. However, other studies in Malawi and South Sudan [11, 13] reported a much higher prevalence of early initiation of breastfeeding compared to the current study. These variations could be explained by differences in the study population, sample size, sampling procedures, study settings and period, sociodemographic characteristics such as access to health information issues, socio-economic status, infrastructures for enhancing health service accessibility, education level and cultural differences in breastfeeding practices $[28,30]$.

The prevalence of early initiation of breastfeeding was lower, particularly for women residing in the Same and Hai districts compared to women residing in the Rombo district. What causes such differences could not be fully established in this study. The variation found between districts in the same region could be explained by differences in environment, culture and beliefs. However, more should be done to assess differences in early initiation of breastfeeding prevalence between these districts.

In this study, women who had a primary education level had a higher prevalence of early initiation of breastfeeding compared to those with secondary education level or above. This was similar to the findings from Bangladesh, where the odds of early initiation of breastfeeding was lesser for women with secondary education level compared to those with non-formal education [31]. Fifty-seven percent of women in the current study with secondary education level were primiparous. In contrast, for women with primary education level, only $23 \%$ were primiparous, which could explain the low prevalence of early initiation of breastfeeding. Being educated can improve early initiation of breastfeeding practice due to increased awareness, however, in our context, educated mothers are wealthier than uneducated and can afford formula milk, so for them, it is a prestige to give their children prelacteal feeds.

Parity was observed to be positively associated with early initiation of breastfeeding. Women who have given birth to two children had a higher prevalence of early initiation of breastfeeding compared to primiparous. This is similar to findings from elsewhere [10-12, 22, $32,33]$. Women who have given birth more than once are likely to have more knowledge and experience on breastfeeding practices compared to nulliparous women, which is expected to influence their current practice [10]. Furthermore, delivery complications are more likely during the first pregnancy, which may end up in separation of the mother from the child, and can delay breastfeeding initiation [10].

Prelacteal feeding was negatively associated with early initiation of breastfeeding. This is consistent with findings from Nepal [17] and in East Ethiopia [34]. Studies have suggested that skilled and trained health workers 
can motivate mothers to practice early initiation of breastfeeding, explain the breastfeeding benefits, and can create awareness on the disadvantages of prelacteal feeding during routine postnatal care immediately after delivery [11, 34-37]. However, in this study, only $28.5 \%$ of 765 women who delivered in the health facilities received breastfeeding support immediately after birth, which could have contributed to prelacteal feeding, hence delay breastfeeding initiation. The health system should be strengthened to ensure that healthcare providers provide breastfeeding support to mothers immediately after delivery. There is a need to investigate the barriers at the health facilities that hinder healthcare providers from providing breastfeeding support to women soon after birth.

\section{Strength and limitations}

By involving participants from most of the districts in the Kilimanjaro region, this study may provide the regional and sub-regional picture of early initiation of breastfeeding practice. However, our findings may not be generalized to other women across the country. This study might have been prone to recall and social desirability bias due to the self-reporting of time of breastfeeding initiation by women. This could have led to underestimation or overestimation of early initiation of breastfeeding practice in the region.

\section{Conclusions}

The prevalence of early initiation of breastfeeding in the Kilimanjaro region was $70 \%$. Though this estimate is good compared to WHO recommendations, it is still below the national targets. The district of residence, maternal education level, parity, and prelacteal feeding were the factors associated with EIBF in this study. To improve early initiation of breastfeeding, healthcare providers at reproductive and child health clinics should emphasize the impact of prelacteal feeding during and breastfeeding support immediately after delivery, particularly women who have given birth for the first time and those with secondary education and above. Interventions to improve early initiation of breastfeeding needs to be strengthened especially in Same and Hai districts. Furthermore, there is a need for qualitative study Same and Hai districts to understand reasons that delays initiation of breastfeeding which eventually leads to low prevalence of early initiation of breastfeeding.

\section{Abbreviations}

ANC: Antenatal Care; EIBF: Early initiation of breastfeeding; KCMUCo: Kilimanjaro Christian Medical University College; WHO: World Health Organization

\section{Acknowledgements}

The authors acknowledge study participants for providing their informed consent and taking part in the parent study. Special thanks to all data collectors and the supervisors for their time and commitment in the entire process of data collection. We also thank the Regional Medical Officer, District Medical Officers, ward, and village executive officers for providing permission and support that made this study a success.

\section{Authors' contributions}

FA and SEM contributed to the design of the study. FA performed the statistical analysis and drafted the manuscript. IM, MM, RM, JMG, SEM participated in the coordination of data collection. IM MM, SEM edited the final draft of the manuscript and approved the final manuscript.

\section{Funding}

The funding to conduct the study was received from Kilimanjaro Christian Medical University College (KCMUCo) under the Institute of Public Health as part of the doctor of medicine training program. Sia E. Msuya was THRiVE-2 faculty and partially supported by the DELTAS Africa Initiative grant number DEL-15-011 to THRiVE-2. The funders did not have any role or influence in the design of the study, data collection, analysis, or interpretation of the results and the development of the manuscript.

\section{Availability of data and materials}

Please contact the author for data requests.

\section{Ethics approval and consent to participate}

Ethical permission was sought from the Kilimanjaro Christian Medical University College Research and Ethical Review Committee. Permission was also sought from the District Medical Officer for each respective district and the ward and village executive officers. Signed informed consent was obtained from participants. Interviews were conducted in a private place around the household, and participants identified using unique identification numbers to ensure confidentiality and privacy.

\section{Consent for publication}

Not applicable.

\section{Competing interests}

None of the authors have any conflict of interest in the content of this manuscript.

\section{Author details}

${ }^{1}$ Institute of Public Health, Department of Epidemiology and Biostatistics, Kilimanjaro Christian Medical University College (KCMUCo), P. O. Box 2240, Moshi, Tanzania. ${ }^{2}$ Better Health for African Mother and Child (BHAMC), P.O. Box 8418, Moshi, Tanzania. ${ }^{3}$ Institute of Public Health, Department,

Department of Community Medicine, Kilimanjaro Christian Medical University College (KCMUCo), P. O. Box 2240, Moshi, Tanzania. ${ }^{4}$ School of Mathematics, Statistics \& Computer Science, University of KwaZulu Natal, Private Bag X01, Scottsville, Pietermaritzburg 3209, South Africa. ${ }^{5}$ Department of Community Medicine, Kilimanjaro Christian Medical Center (KCMC), P. O. Box 3010, Moshi, Tanzania.

Received: 15 March 2020 Accepted: 2 September 2020

Published online: 10 September 2020

\section{References}

1. Derso T, Biks GA, Tariku A, Tebeje NB, Gizaw Z, Muchie KF, et al. Correlates of early neonatal feeding practice in Dabat HDSS site, Northwest Ethiopia. Int Breastfeed J. 2017;12:25

2. UNICEF W. Capture the moment early initiation of breastfeeding: the best start for every newborn. New York: UNICEF; 2018.

3. NEOVITA Study Group. Timing of initiation, patterns of breastfeeding, and infant survival: prospective analysis of pooled data from three. Lancet Glob Health. 2016:4(4):e266-75.

4. Debes AK, Kohli A, Walker N, Edmond K, Mullany LC. Time to initiation of breastfeeding and neonatal mortality and morbidity: a systematic review. BMC Public Health. 2013;13:S19.

5. Smith ER, Hurt L, Chowdhury R, Sinha B, Fawzi W, Edmond KM, et al. Delayed breastfeeding initiation and infant survival: a systematic review and meta- analysis. PLoS One. 2017;12(7):e0180722.

6. Phukan D, Ranjan M, Dwivedi LK. Impact of timing of breastfeeding initiation on neonatal mortality in India. Int Breastfeed J. 2018;13:27. 
7. Tulay A, Bosi B, Eriksen KG, Sobko T, Wijnhoven TMA. Breastfeeding practices and policies in WHO European region member states. Public Health Nutr. 2015;19(4):753-64.

8. Alebel A, Dejenu G, Mullu G, Abebe N, Gualu T, Eshetie S. Timely initiation of breastfeeding and its association with birth place in Ethiopia: a systematic review and meta-analysis. Int Breastfeed J. 2017;12:44.

9. Hassan AA, Taha Z, Ahmed MAA, Ali AAA, Adam I. Assessment of initiation of breastfeeding practice in Kassala. Eastern Sudan. 2018;13:34.

10. Mukora-Mutseyekwa F, Gunguwo H, Mandigo RG, Mundagowa P. Predictors of early initiation of breastfeeding among Zimbabwean women: secondary analysis of ZDHS 2015. Matern Health Neonatol Perinatol. 2019;5:2.

11. Nkoka O, Ntenda PAM, Kanje V, Milanzi EB, Arora A. Determinants of timely initiation of breast milk and exclusive breastfeeding in Malawi: a populationbased cross-sectional study. Int Breastfeed J. 2019;14:37.

12. Berde AS, Yalcin SS. Determinants of early initiation of breastfeeding in Nigeria: a population- based study using the 2013 demograhic and health survey data. BMC Pregnancy Childbirth. 2016;16:32.

13. Tongun JB, Sebit MB, Mukunya D, Ndeezi G, Nankabirwa V, Tylleskar T, et al. Factors associated with delayed initiation of breastfeeding: a cross-sectional study in South Sudan. Int Breastfeed J. 2018;13:28.

14. Ministry of Health, Community Development, Gender Elderly and Children (MoHCDGEC) [Tanzania Mainland, Ministry of Health (MoH) [Zanzibar], National Bureau of statistics (NBS), Office of the Chief Government Statician (OCGS). Tanzania demographic and health survey and malaria indicator survey (TDHSMIS) 2015-16; 2016.

15. Boerma T, Requejo J, Amouzou A, George A, Agyepong I, Barroso C, et al. Countdown to 2030 tracking progress towards universal covarage for reproductive, newborn and child health. Lancet. 2018;391(10129):1538-48.

16. Ministry of Health and Social Welfare. National Road map Strategic Plan to improve reproductive, maternal, newborn and adolescent health in Tanzania (2016-2020); 2016.

17. Khanal V, Scott JA, Lee AH, Karkee R, Binns CW. Factors associated with early initiation of breastfeeding in Western Nepal. Int J Environ Res Public Health. 2015;12(8):9562-74.

18. Tilahun G, Degu G, Azale T, Tigabu A. Prevalence and associated factors of timely initiation of breastfeeding among mothers at Debre Berhan town, Ethiopia: a cross-sectional study. Int Breastfeed J. 2016;11:27.

19. Hailemariam TW, Adeba E, Sufa A. Predictors of early breastfeeding initiation among mothers of children under 24 months of age in rural part of West Ethiopia. BMC Public Health. 2015:15:1076.

20. Alzaheb RA. A review of the factors associated with the timely initiation of breastfeeding and exclusive breastfeeding in the Middle East. Clin Med Insights. 2017;11:11795565177488912.

21. Ahmed AE, Salih OA. Determinants of the early initiation of breastfeeding in the Kingdom of Saudi Arabia. Int Breastfeed J. 2019;14:13.

22. Sharma IK, Byrne A. Early initiation of breastfeeding : a systematic literature review of factors and barriers in South Asia. Int Breastfeed J. 2016;11:17.

23. Kambale RM, Buliga JB, Isia NF, Muhimuzi AN, Battisti O, Mungo BM. Delayed initiation of breastfeeding in Bukavu, south Kivu, eastern Democratic Republic of the Congo: a cross-sectional study. Int Breastfeed J. 2018:13:6

24. National Bureau of Statistics (NBS). The 2012 population and housing census. Basic demographic and socio-economic profile; 2014.

25. World Health Organization. Infant and Young Child Feeding A tool for assessing national practices policy program. 2003.

26. Exavery A, Kanté AM, Hingora A, Phillips JF. Determinants of early initiation of breastfeeding in rural Tanzania. Int Breastfeed J. 2015;10:27.

27. Mekonen L, Seifu W, Shiferaw Z. Timely initiation of breastfeeding and associated factors among mothers of infants under 12 months in South Gondar zone, Amhara regional state, Ethiopia; 2013. Int Breastfeed J. 2018; 13:17

28. Ezeh OK, Ogbo FA, Stevens GJ, Tannous WK, Uchechukwu OL, Ghimire PR, et al,. Factors Associated with the Early Initiation of Breastfeeding in Economic Community of West African States (ECOWAS). Nutrients. 2019;11(11):2765

29. Khatun H, Comins CA, Shah R, Islam MM, Choudhury N, Ahmed T. Uncovering the barriers to exclusive breastfeeding for mothers living in Dhaka's slums: a mixed method study. Int Breastfeed J. 2018;1-11.

30. Abie BM, Goshu YA. Early initiation of breastfeeding and colostrum feeding among mothers of children aged less than 24 months in Debre Tabor, northwest Ethiopia: a cross-sectional study. BMC Research Notes. 2019;12:65.
31. Islam A, Mamun A, Hossain M, Bharati P, Saw A, Lestrel PE et al. Prevalence and factors associated with early initiation of breastfeeding among Bangladeshi mothers: A nationwide cross-sectional study. PLoS One. 2019; 14(4).

32. Ahmed KY, Page A, Arora A, Ogbo FA. Trends and determinants of early initiation of breastfeeding and exclusive breastfeeding in Ethiopia from 2000 to 2016. Int Breastfeed J. 2019;14:40.

33. John JR, Mistry SK, Kebede G, Manohar N, Arora A. Determinants of early initiation of breastfeeding in Ethiopia: a population- based study using the 2016 demographic and health survey data. BMC Pregnancy Childbirth. 2019; 19:69.

34. Tewabe T. Timely initiation of breastfeeding and associated factors among mothers in Motta town, East Gojjam zone, Amhara regional state, Ethiopia, 2015: a cross-sectional study. BMC Pregnancy Childbirth. 2016;16(1):314.

35. Karim F, Billah SM, Ahsanul M, Chowdhury K, Zaka N, Manu A, El Arifeen S, et al. Initiation of breastfeeding within one hour of birth and its determinants among normal vaginal deliveries at primary and secondary health facilities in Bangladesh: A case- observation study. PLoS One. 2018; 13(8).

36. Belachew A. Timely initiation of breastfeeding and associated factors among mothers of infants age 0-6 months old in Bahir Dar City, Northwest, Ethiopia, 2017: a community based cross-sectional study. Int Breastfeed J. 2019;14:5

37. Ndirangu MN, Gatimu SM, Mwinyi HM, Kibiwott DC. Trends and factors associated with early initiation of breastfeeding in Namibia: analysis of the Demographic and Health Surveys 2000 - 2013. BMC Pregnancy childbirth. 2018;18:17.

\section{Publisher's Note}

Springer Nature remains neutral with regard to jurisdictional claims in published maps and institutional affiliations.
Ready to submit your research? Choose BMC and benefit from:

- fast, convenient online submission

- thorough peer review by experienced researchers in your field

- rapid publication on acceptance

- support for research data, including large and complex data types

- gold Open Access which fosters wider collaboration and increased citations

- maximum visibility for your research: over $100 \mathrm{M}$ website views per year

At $\mathrm{BMC}$, research is always in progress.

Learn more biomedcentral.com/submission 